\title{
The Role of Negative-Pressure Wound Therapy in Lower-Limb Reconstruction
}

Renita Sirisena ${ }^{1}$ Gregory Lucien Bellot ${ }^{1}$ Mark Edward Puhaindran ${ }^{1}$

\begin{abstract}
Address for correspondence Dr. Renita Sirisena, MRCS (Eng), Department of Hand and Reconstructive Microsurgery, National University Hospital, NUHS Tower Block, 1E Kent Ridge Road Level 11, Singapore 119228, Singapore (e-mail: renita_sirisena@nuhs.edu.sg).
\end{abstract}

\begin{abstract}
Keywords

- lower-limb reconstruction

- lower-limb trauma

- negative-pressure wound therapy

- tissue resurfacing

Negative-pressure wound therapy (NPWT) has gained increasing popularity among clinicians since its introduction in 1997 as a potential aid to wound healing. Multiple benefits of NPWT have since been proven in studies, including increase in granulation tissue formation, decrease in bacterial load, and the improved survival of flaps. With our increasing use and greater understanding of the tissue and cellular changes that occur in a wound treated with NPWT, our lower-limb reconstructive practice has also evolved. Although controversial, the definite timing for lower-limb reconstruction has stretched from 72 hours to longer than 2 weeks as NPWT contains the wound within a sterile, closed system. It has also shown to decrease the rate of infection in open tibia fractures. Previously, a large number of critical defects of the lower limb would require free tissue transfer for definitive reconstruction. NPWT has reduced this rate by more than $50 \%$ and has allowed for less complicated resurfacing procedures to be performed instead.
\end{abstract}

\section{Introduction}

Lower-limb reconstruction in the setting of trauma is challenging. With advances in the understanding of wound healing physiology, there have been a large number of wound healing aids that have been introduced. Negative-pressure wound therapy (NPWT) is one such aid that has been increasing in popularity among clinicians and has changed the way we now treat lower-limb injuries in trauma.

In this review article, we aim to look through the evidence behind the use of NPWT in lower-limb reconstruction and how our current clinical practices have changed as a result of NPWT and the cellular and tissue responses to NPWT.

\section{History of Negative-Pressure Wound Therapy}

Morykwas et al introduced the concept of a subatmospheric pressure method for the treatment of wounds: vacuumassisted closure (VAC). ${ }^{1}$ This technique was developed as a means to expedite the rate of wound healing by secondary intention. In his porcine model, they found that wounds treated with VAC had increased blood flow levels, increased granulation tissue formation, decreased tissue bacterial counts, and significantly increased survival rates of random pattern flaps.

VAC was initially designed to aid the healing of chronic wounds, but it has progressively been used for the management of all types of wounds, ulcers, and burns. Given the increase in the usage of NPWT, there have been multiple advances in dressing technology related to NPWT such as silicon interfaces, open-cell foam types with differing pore densities, and an irrigation system to allow the instillation of fluids into the wound. Given all the advances in NPWT, there has been a global increase in the number of such devices being used and the market continues to grow.

\section{Technique of Negative-Pressure Wound Therapy Application}

The technique of NPWT application is relatively straightforward. After thorough debridement of the wound, proper hemostasis, and coverage of all critical structures such as blood vessels and nerves, the wound bed is ready for application of the
DOI https://doi.org/ $10.1055 / \mathrm{s}-0039-1687922$ ISSN 0970-0358.
C2019 Association of Plastic Surgeons of India
License terms

$($ () (1) $\Theta \circledast$ 
$\mathrm{NPWT}^{2}$ ( - Fig. 1). NPWT consists of continuous or intermittent subatmospheric pressure applied to an open-cell foam that is sealed in an occlusive dressing (-Fig. 2). This creates a sterile, closed, vacuum-sealed environment that is connected to a vacuum pump. The negative pressure (50-175 $\mathrm{mm} \mathrm{Hg}$ ) and the mode used (intermittent or continuous) can be customized according to the patient and wound type.

To prevent the surrounding intact skin from becoming macerated, the open-cell foam should be cut smaller than the actual wound size and can be halved to reduce the thickness of the foam (-Fig. 3). In certain cases, the wound edge can be lined with a protective hydrocolloid dressing to further prevent skin maceration (-Fig. 4). Once the open-cell foam has been applied to the wound, occlusive dressing is placed and a hole is cut into the dressing to allow for creation of the vacuum-sealed environment by the application of the trackpad ( - Fig. 5). Once the machine is turned on, one should see the open-cell foam contract and no leak should be noted on the machine (-Fig. 6 ). NPWT should be changed ideally in the operating theater or by the bedside every 72 to 120 hours.

Wounds that are contraindicated ${ }^{3}$ for the use of NPWT include (1) actively bleeding wounds, (2) inadequately debrided bone and soft tissue infections, (3) malignant wounds, (4) nonenteric and unexplored fistulae, and (5) necrotic tissue with eschar present. Before the application of NPWT, all wounds require a proper debridement, adequate hemostasis, and protection of neurovascular structures.

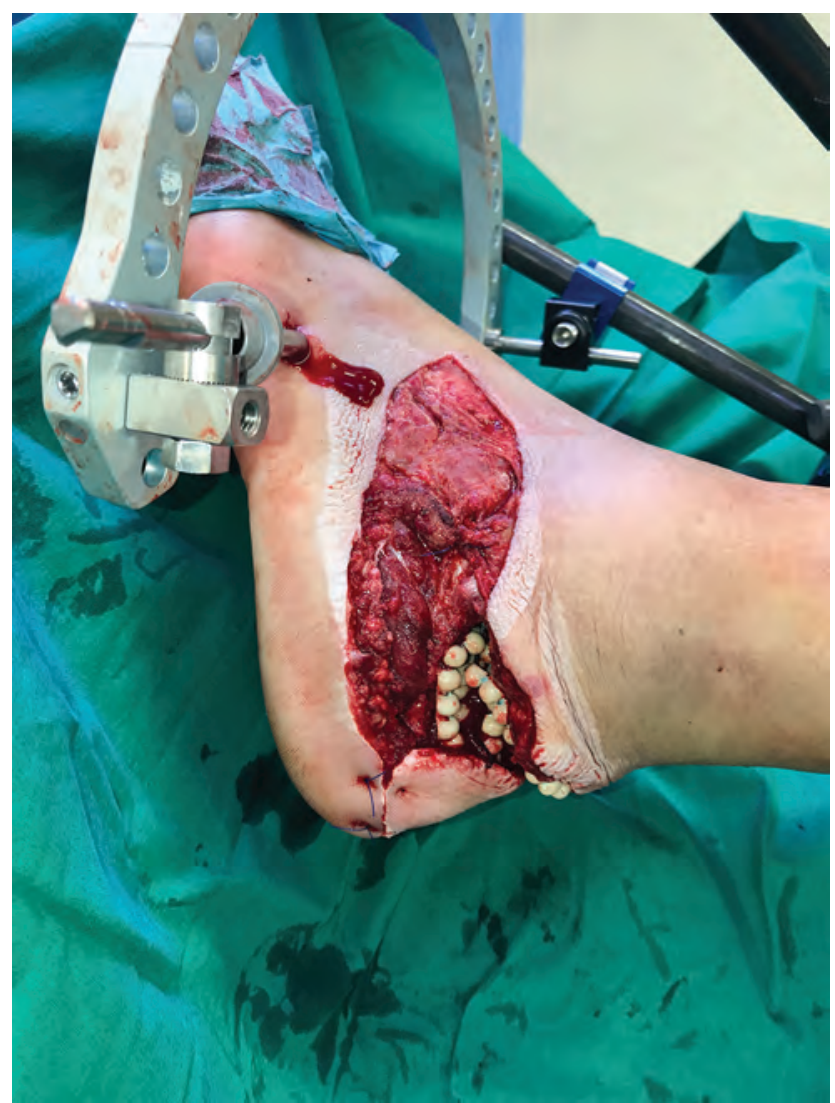

Fig. 1 An open trimalleolar ankle fracture with a critical defect over the lateral ankle underwent external fixation and debridement. Antibiotic-laden cement beads were packed into the critical defect during the second debridement and washout.

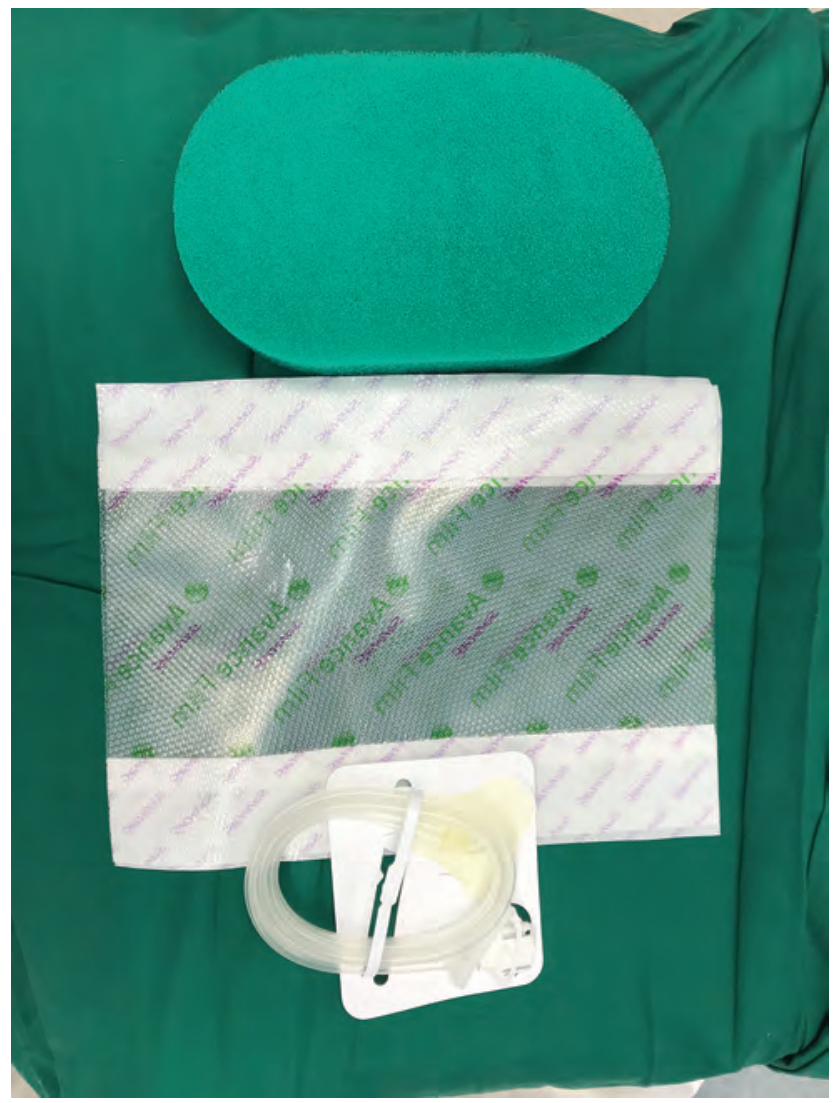

Fig. 2 These are the materials used when applying negative-pressure wound therapy-open-cell foam, occlusive dressing, and the trackpad.

\section{Clinical Benefits of Negative-Pressure Wound Therapy}

\section{Timing of Reconstruction}

Previously according to Godina, early microsurgical reconstruction within 72 hours from trauma increased flap survival, reduced infection, and shortened hospitalization stay of patients. ${ }^{4}$ However, this notion has been challenged by many authors. Some have found that reconstruction can be performed up to 2 weeks from injury ${ }^{5}$ and that flap survival is not time dependent. ${ }^{6}$ Thus, the timing of lower-limb reconstruction in trauma is still controversial.

The availability of NPWT has allowed us to stretch the duration till definite lower-limb reconstruction. Exposed fractures may predispose to increased rates of wound infection and adverse outcomes, and this has driven the need for urgent coverage. ${ }^{7}$ NPWT allows for temporary coverage of the wound in a sterile environment while applying negative pressure at the wound bed to reduce tissue edema, promote granulation tissue, and enhance bacterial clearance. This has resulted in an increase in NPWT being used for open lower-limb fractures before reconstruction. ${ }^{4}$

\section{Effect on Infection Rates}

The initial work by Morykwas et al showed that NPWT increased bacterial clearance in the porcine model with a reduction in the daily quantitative bacterial counts over a 5-day treatment period. ${ }^{1}$ These results were replicated 


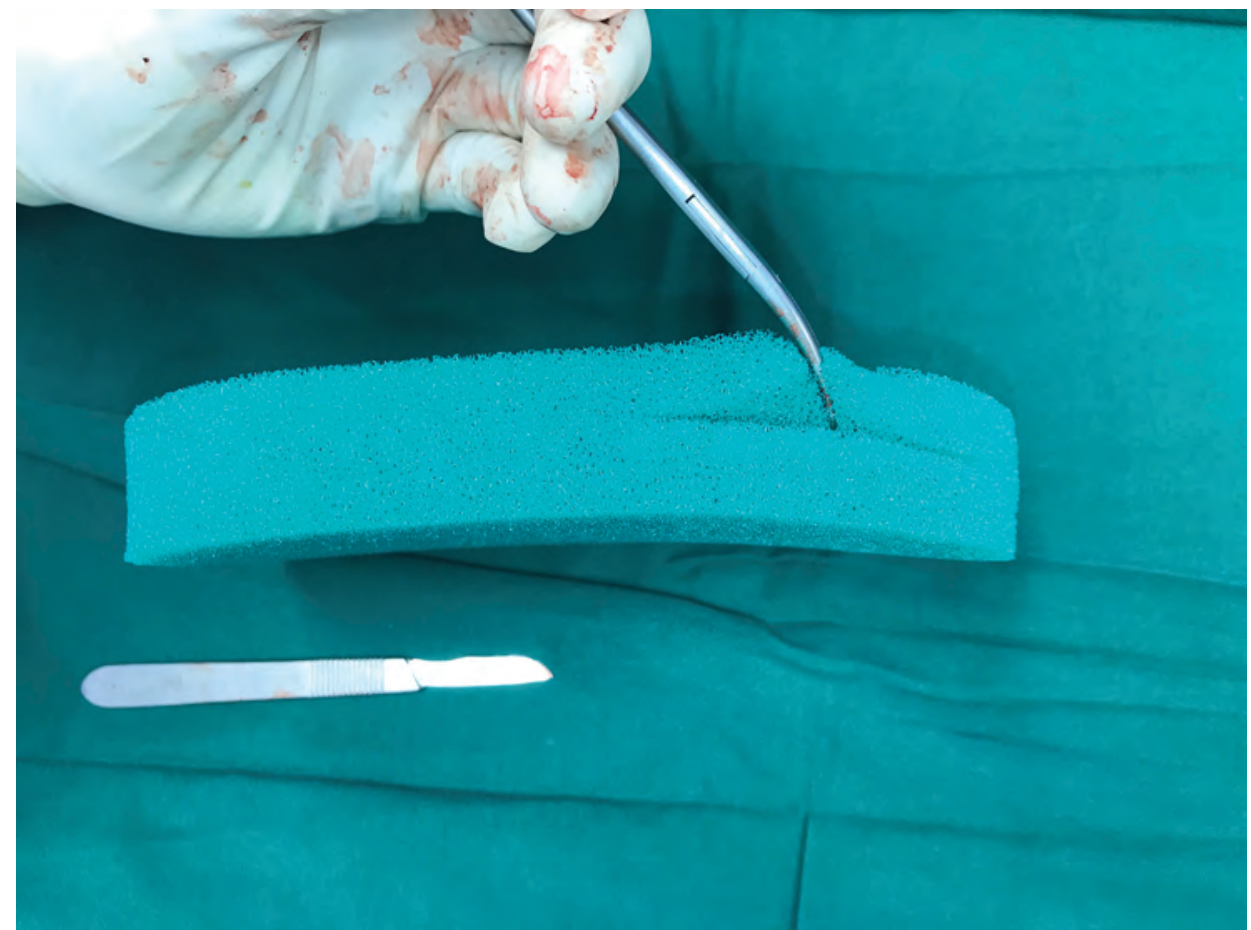

Fig. 3 For wounds that are shallow, the open-cell foam can be halved before application. Ensuring that the foam is smaller than the actual wound size also prevents surrounding skin maceration.

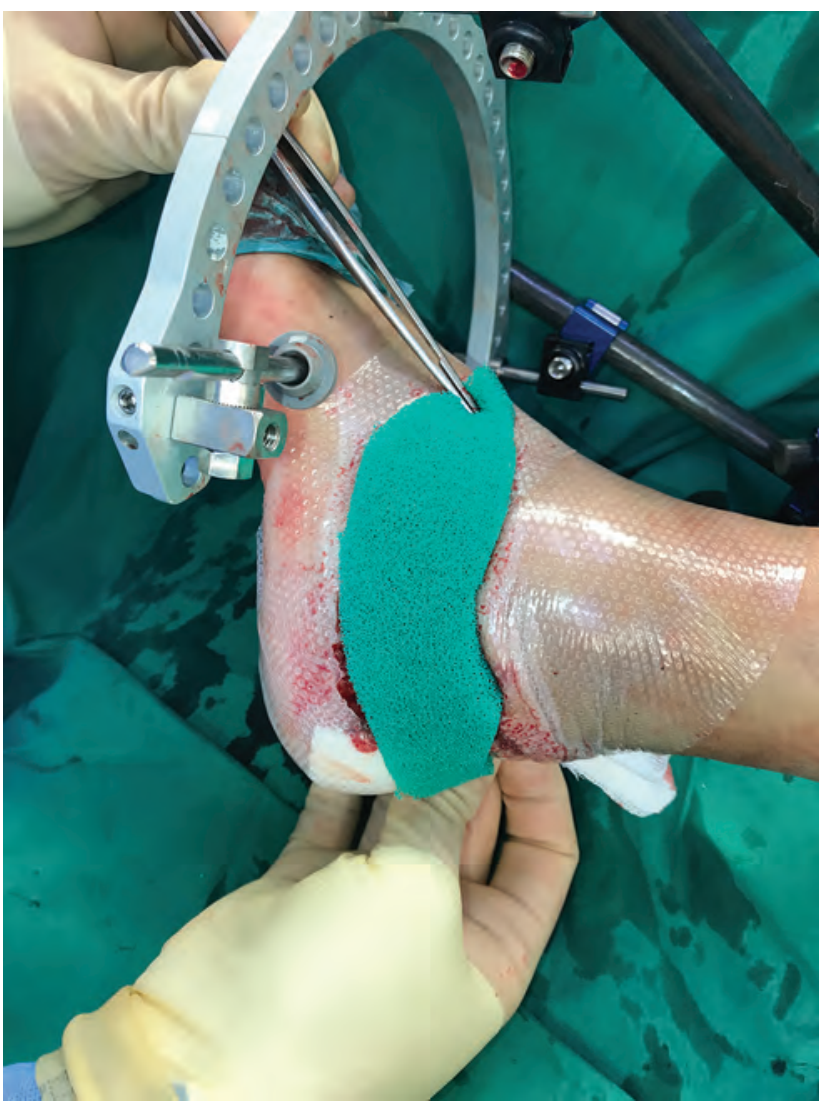

Fig. 4 The wound edges are further lined with a protective hydrocolloid dressing to prevent surrounding skin maceration.

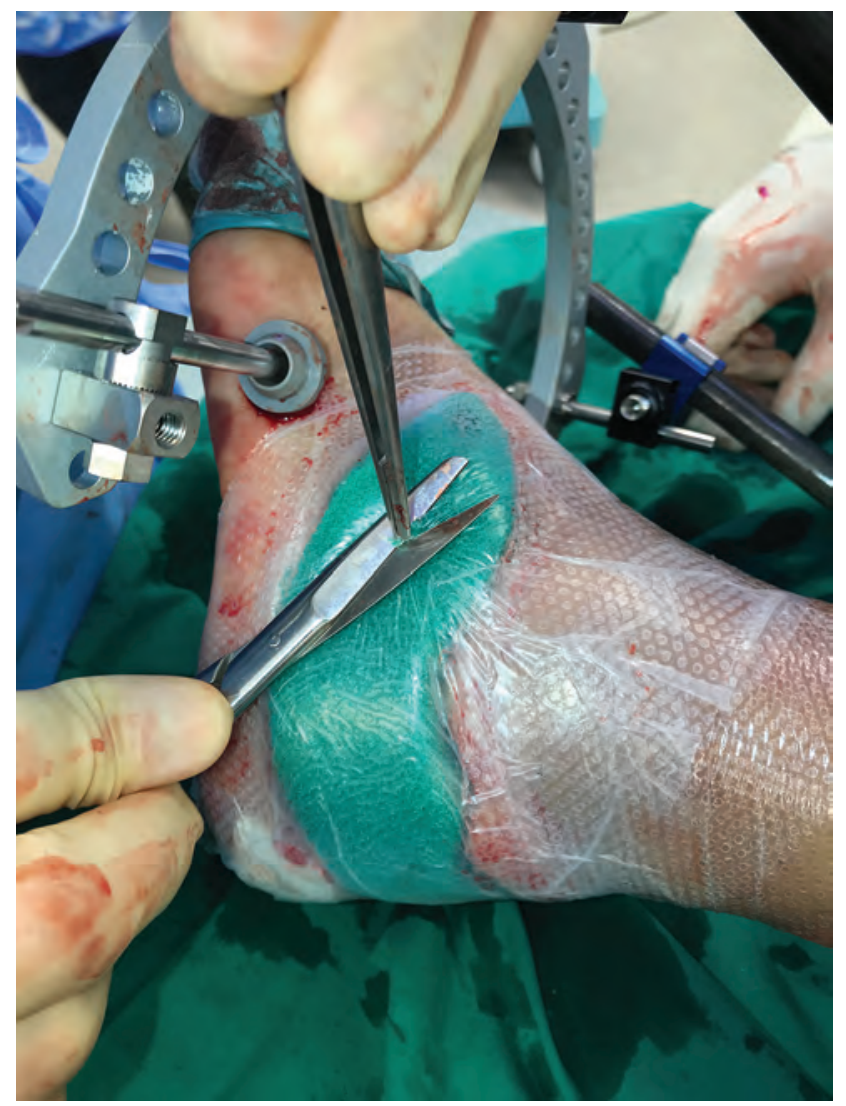

Fig. 5 After applying the occlusive dressing over the foam dressing, a hole is cut in the dressings to allow for application of the trackpad to create the vacuum-sealed environment. 


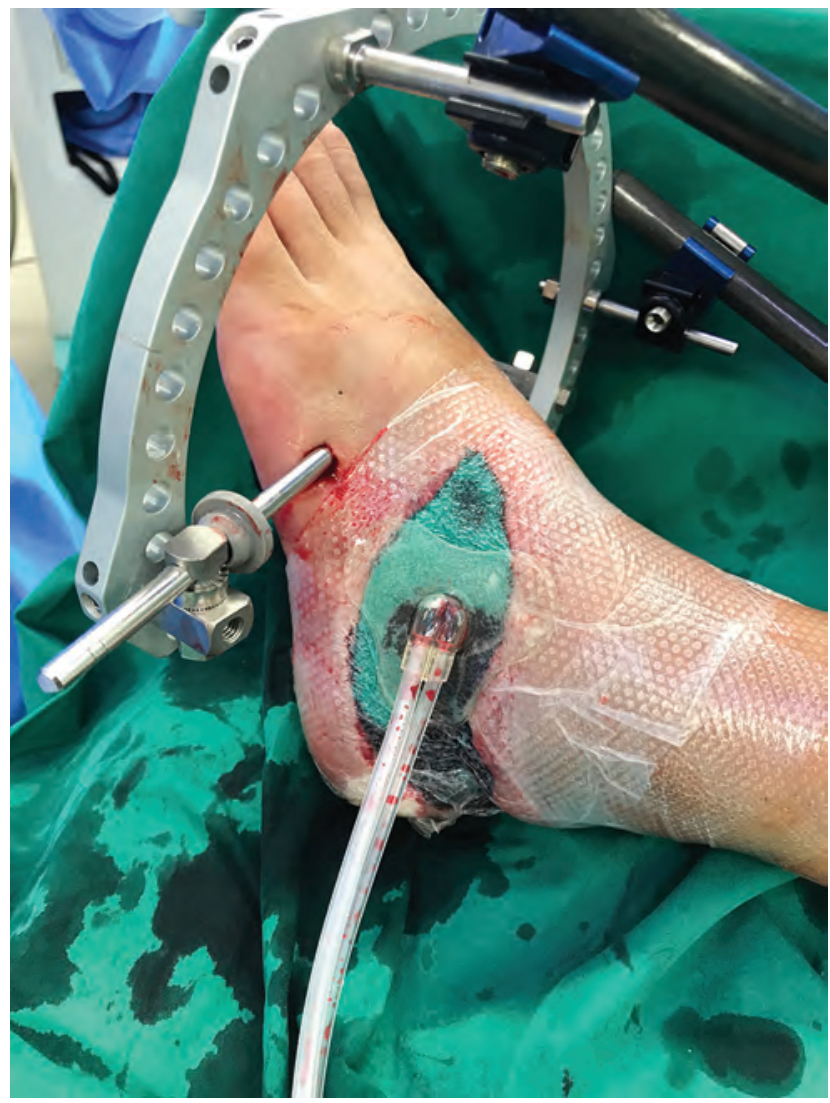

Fig. 6 On turning the negative-pressure wound therapy machine on, the open-cell foam is seen to contract and the leak status can be observed from indicators on the machine.

in a subsequent human study that they conducted on 300 wounds, ranging from acute and subacute to chronic. ${ }^{8}$

Since then, there has been conflicting evidence in the literature regarding the effect of NPWT on infection rates. There have been multiple studies published showing no significant difference between infection rates in wounds treated with NPWT and conventional dressings. ${ }^{9,10}$ Yet, there has also been more recent evidence showing that NPWT has helped significantly decrease the rate of infection when used in the treatment of open tibial fractures.

Joethy et al conducted a retrospective analysis of Gustilo IIIB tibial fractures between two periods of time: 2003-2004 and 2008-2009. ${ }^{11}$ All patients underwent free flap reconstruction, with the earlier cohort being treated with occlusive dressings as compared with the later cohort who had NPWT. There was a statistically significant difference in infection rates, with the NPWT cohort having roughly one-third the rate of infection (10\% [5/51] vs. 33\% [6/18], $p=0.029)$.

This study was further supported by a prospective randomized study by Stannard et al, which found a significantly lower deep infection rate in open fractures covered with NPWT compared with conventional dressings. ${ }^{12}$ Similar results were also found by Blum et al who concluded that NPWT substantially decreases deep infection when used in the soft tissue management of open tibial fractures. ${ }^{13}$

\section{Effect on Flap Failures and the Need for Complicated Reconstructive Procedures}

NPWT has been reported to increase granulation tissue formation and blood flow to the wound bed. It has also shown to improve the survival of random patterned flaps in its original animal study. ${ }^{1}$ When used in the management of open Gustilo IIIB tibia fractures, Joethy et al found a lower rate of flap failures as compared with when occlusive dressings were used $(6 \%[3 / 51]$ vs. $11 \%[2 / 18]) .{ }^{11}$ However, in this study, this result was not noted to be statistically significant.

Lower-limb trauma wounds with exposed tendon, bone, and implants would usually require flap reconstruction. However, with the increased use of NPWT in the management of such cases, there has been a growing number of publications showing a reduction in the need for free tissue transfers. DeFranzo et al looked at the use of NPWT in wounds with critically exposed structures in 75 patients. ${ }^{14}$ All wounds were closed with delayed primary closure, split-thickness skin grafts, or regional flaps without the need for free tissue transfer.

Herscovici et al prospectively studied the use of NPWT in 21 high-energy soft tissue wounds where flap reconstructive procedures would have originally been performed. After an average of 4.1 sponge changes over an average of 19.3 days (5-84 days), further reconstructive surgery was avoided for $57 \%$ of the wounds. ${ }^{15}$ Other than the decrease in the overall need for flap reconstructive procedures, it has also provided an alternative option for otherwise non-salvageable wounds in medically unfit patients. Despite all the benefits of NPWT, it is important to remember that it does not replace the need for formal wound debridement.

In the below clinical scenario, an open wound was sustained over the left anterior tibia, which eventually became infected and broke down ( - Fig. 7). After a proper debridement, the tibia devoid of periosteum ( - Fig. 8) was exposed, and the use of NPWT allowed us to delay the need for flap reconstruction until the wound was clear of infection. A bipedicled perforator flap ( $\boldsymbol{- \text { Fig. 9) }}$ ) based on the posterior tibial artery was performed to resurface the anterior tibial wound with split-thickness skin grafting ( - Fig. 10) applied over the gastrocnemius muscle.

\section{Our Current Understanding of Basic Science}

Although widely used in clinical practice, the mechanisms by which NPWT promotes wound healing remain under investigation. ${ }^{16-18}$ Its beneficial result appears to be the consequence of multiples effects triggered at the tissue and cellular levels supporting the healing mechanism..$^{16,17}$

\section{Macro- and Micro-deformation-Induced Angiogenesis}

The earliest effects that were investigated were related to the mechanical stress that NPWT applied to the wound as it was suspected to be an important factor in the positive effects observed on the healing process. One of the mechanical effects imposed by NPWT on the wound edges 


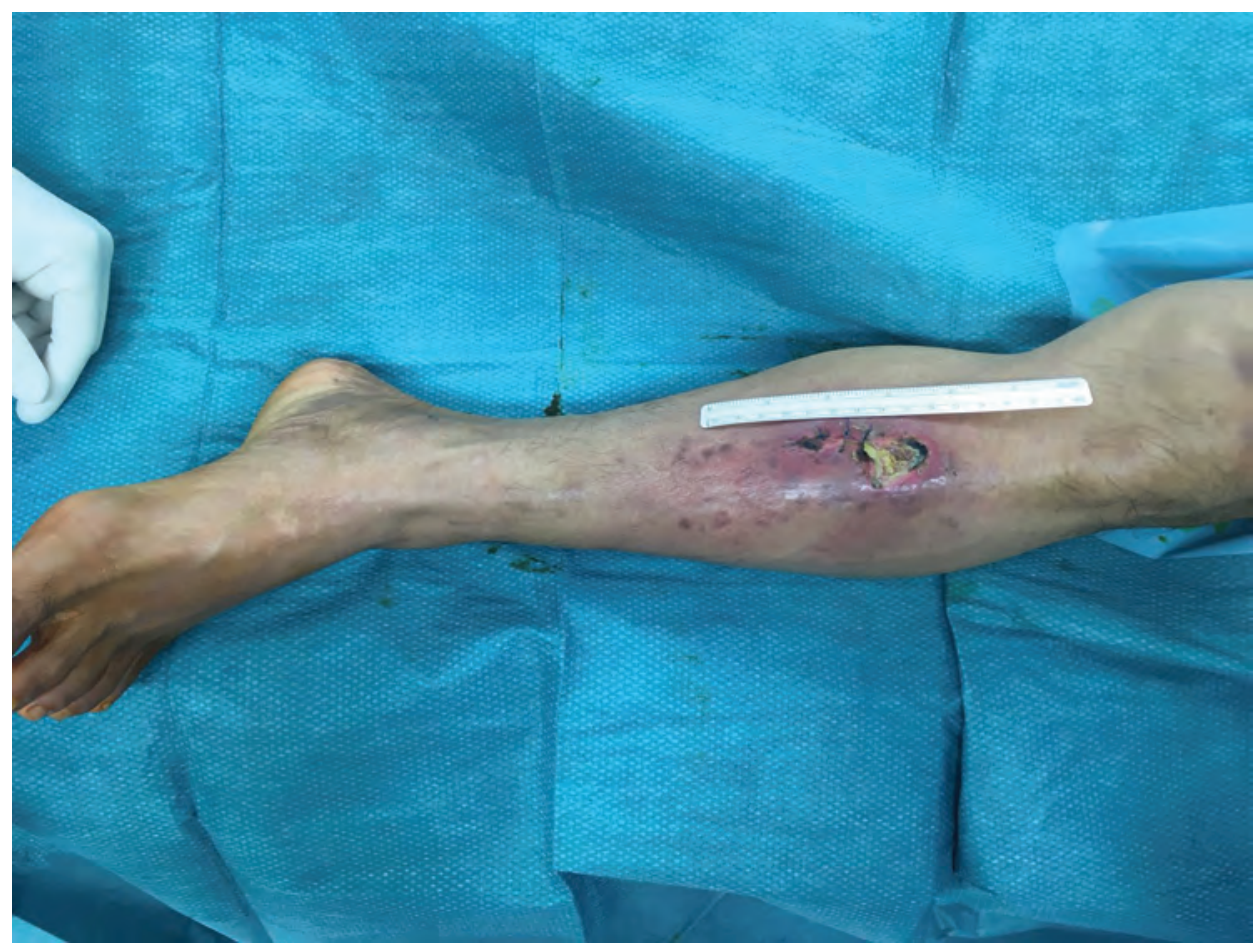

Fig. 7 The left distally based anterior tibia wound was initially sutured. It subsequently became infected 2 weeks later and the patient required readmission for surgical debridement and intravenous antibiotics.

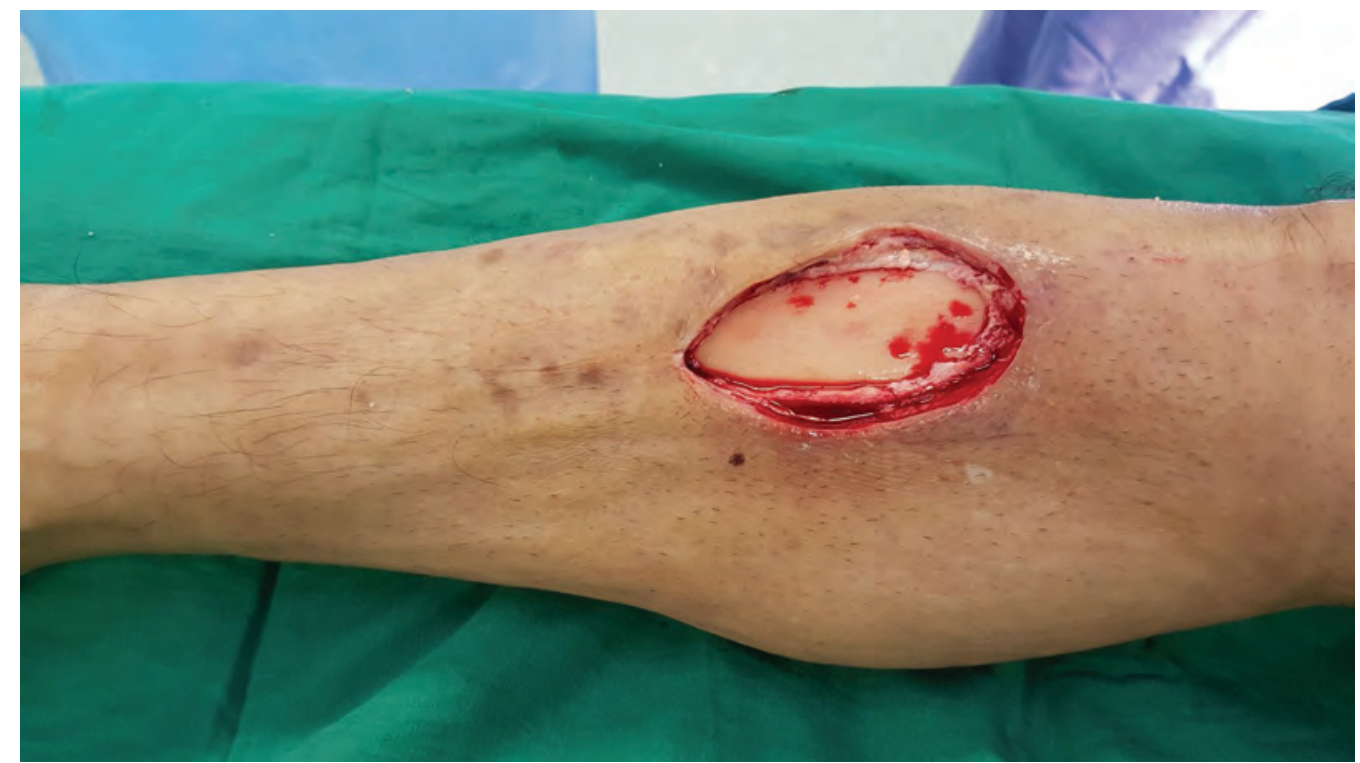

Fig. 8 Post-debridement, the critical defect over the tibia devoid of periosteum was $10 \mathrm{~cm}(\mathrm{~L}) \times 6 \mathrm{~cm}(\mathrm{~W})$. The wound was covered with negative-pressure wound therapy thereafter until intraoperative cultures were negative.

is macro-deformation ${ }^{17}$ : this results in the application of a compressive force on the tissues that promote wound contraction ${ }^{19}$ and can potentially reduce edema by pushing fluids away. ${ }^{20}$ Although not considered as the major contributor of wound healing promoted by NPWT, the effect of macro-deformation plays a part in its efficiency. ${ }^{16}$

The second type of mechanical effect triggered by NPWT is micro-deformation: This results from the interface created between the wound bed and the foam material used to apply a uniform negative pressure on the wound bed. ${ }^{21}$ This effect has been directly correlated with an improvement in blood perfusion, angiogenesis, and cell proliferation. ${ }^{22-25}$ Although poorly understood, it has been shown to stimulate basic fibroblast growth factor upregulation and the downstream activation of ERK1/2, indicating cell proliferation stimulated through mitogen-activated kinase pathway..$^{24,26}$ In addition, micro-deformation stimulates angiogenesis and vascular remodeling through upregulation of vascular endothelial growth factor (VEGF), which is critical in the elongation 


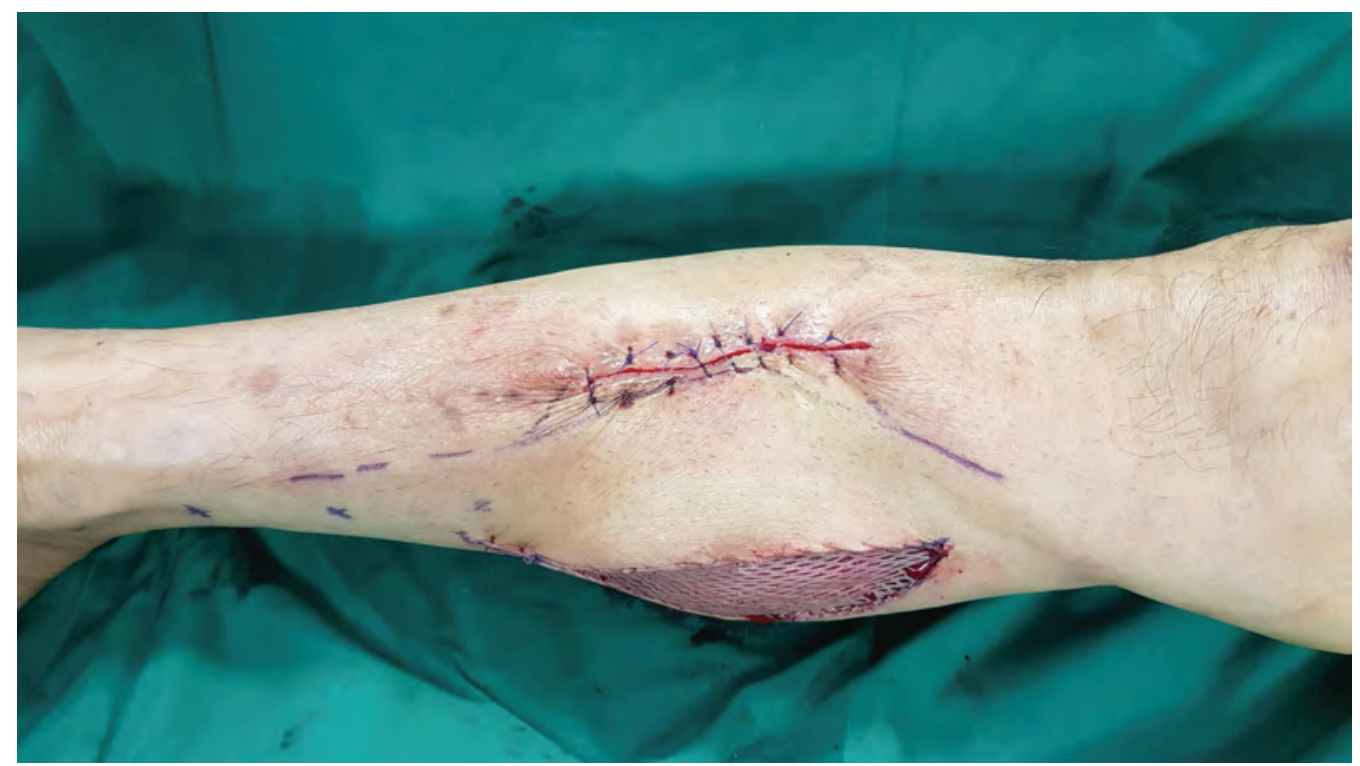

Fig. 9 A bipedicled flap based on the perforators of the posterior tibial artery was raised to resurface the critical defect over the anterior tibia.

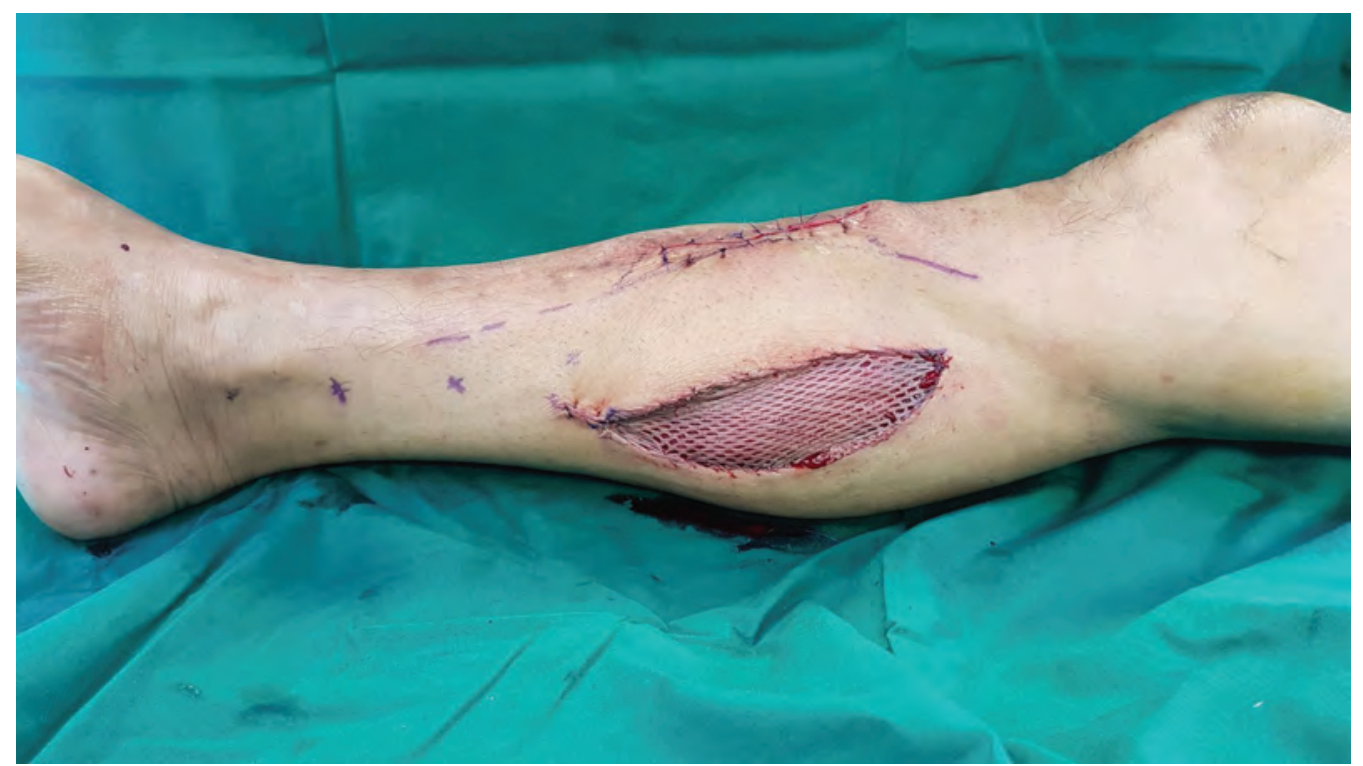

Fig. 10 Split-thickness skin graft was harvested from the left medial thigh and meshed 1:1.5. Negative-pressure wound therapy was placed over the skin graft recipient site and removed after 5 days once $100 \%$ graft take was established.

and proliferation of endothelial cells, and also plays an important role in the regulation of inflammation. ${ }^{22,26,27}$ Other proteins upregulated with NPWT treatment include intercellular adhesion molecule $1-$ a glycoprotein expressed on the surface of endothelial and immune cells that play a role in inflammation and transmigration of immune cells through the endothelial barrier. ${ }^{28}$ Macrophage migration inhibitory factor is also upregulated, and this proinflammatory lymphokine has the ability to regulate macrophage migration, function, and regulation of the antioxidant response elements system. ${ }^{28-30}$

\section{Hypoxia Signaling and Angiogenesis}

NPWT has a positive impact on angiogenesis, and this has been linked to the modulation of the hypoxic response.
Hypoxia-inducible factor $1 \alpha$, a master regulator of hypoxia signaling, has been observed to have decreased expression ${ }^{31}$ whereas angiogenic factors such as VEGF and angiopoietin 2 are observed to increase. These events cause the regulation of hypoxia within the wound bed, optimizing the shape and function of neovascularization. NPWT may destabilize blood vessels in the early phase of wound healing and allow for the formation of new vessels at the later phases of wound healing, allowing the establishment of mature blood vessels. ${ }^{32}$ Other factors involved in angiogenesis such as platelet-derived growth factor and epidermal growth factor (EGF) have also been shown to increase with NPWT. ${ }^{33}$ Angiogenesis is critical in the promotion of wound healing and is also an important parameter in the formation of granulation tissue. 


\section{Hypoxia Signaling and Lactate Production}

Another effect induced by hypoxia is lactate production, which is an important metabolite involved in wound healing. ${ }^{34}$ As lactate is able to act as a surrogate to hypoxia and stimulate the hypoxic pathyways, ${ }^{35,36}$ it is able to modulate angiogenesis and promote collagen deposition for granulation tissue formation. ${ }^{34,37}$

The major mechanisms modulated by NPWT comprise pathways regulating inflammation, angiogenesis, and extracellular matrix formation. ${ }^{37}$ Whereas these are the major pathways that have been identified in the cellular mechanisms triggered by negative pressure, gaps remain to be filled and new questions arise about how all these events are interconnected to fully assess the impact of NPWT on tissue repair. ${ }^{16,17}$ Mechanotransduced signals, energetic metabolism modification regulated by NPWT, are among the most interesting but still poorly understood mechanisms involved in NPWT. By understanding them, it may be possible to further modify them, with the eventual goal of further aiding wound healing.

\section{Conclusion}

The use of NPWT in the management of complex lower-limb wounds has been increasing over the past two decades since its initial introduction. There has been a growing body of evidence to show its efficacy, how it has changed current treatment practices in multiple centers globally as well as an evolving understanding of the science behind it. NPWT has proven to be a useful adjunct in the treatment of lower-limb trauma, and its use has been included in our institution's standardized guidelines for the management of open lower-limb fractures. At present, better evidence is required to further justify the growing use of NPWT in lower-limb reconstructions.

\section{Financial Support and Sponsorship \\ None.}

\section{Conflicts of Interest}

There are no conflicts of interest.

\section{References}

1 Morykwas MJ, Argenta LC, Shelton-Brown EI, McGuirt W. Vacuum-assisted closure: a new method for wound control and treatment: animal studies and basic foundation. Ann Plast Surg 1997;38(6):553-562

2 Kanakaris NK, Thanasas C, Keramaris N, Kontakis G, Granick MS, Giannoudis PV. The efficacy of negative pressure wound therapy in the management of lower extremity trauma: review of clinical evidence. Injury 2007;38(Suppl 5):S9-S18

3 Andros G, Armstrong DG, Attinger CE, et al; Tucson Expert Consensus Conference. Consensus statement on negative pressure wound therapy (V.A.C. therapy) for the management of diabetic foot wounds. Ostomy Wound Manage 2006;(Suppl):1-32

4 Godina M. Early microsurgical reconstruction of complex trauma of the extremities. Plast Reconstr Surg 1986;78(3):285-292

5 Yaremchuk MJ, Brumback RJ, Manson PN, Burgess AR, Poka A, Weiland AJ. Acute and definitive management of traumatic osteocutaneous defects of the lower extremity. Plast Reconstr Surg 1987;80(1):1-14
6 Khouri RK, Shaw WW. Reconstruction of the lower extremity with microvascular free flaps: a 10-year experience with 304 consecutive cases. J Trauma 1989;29(8):1086-1094

7 Liu DS, Sofiadellis F, Ashton M, MacGill K, Webb A. Early soft tissue coverage and negative pressure wound therapy optimises patient outcomes in lower limb trauma. Injury 2012;43(6):772-778

8 Argenta LC, Morykwas MJ. Vacuum-assisted closure: a new method for wound control and treatment: clinical experience. Ann Plast Surg 1997;38(6):563-576, discussion 577

9 Weed T, Ratliff C, Drake DB. Quantifying bacterial bioburden during negative pressure wound therapy: does the wound VAC enhance bacterial clearance? Ann Plast Surg 2004;52 (3):276-279, discussion 279-280

10 Mouës CM, Vos MC, van den Bemd GJ, Stijnen T, Hovius SE. Bacterial load in relation to vacuum-assisted closure wound therapy: a prospective randomized trial. Wound Repair Regen 2004;12(1):11-17

11 Joethy J, Sebastin SJ, Chong AK, Peng YP, Puhaindran ME. Effect of negative-pressure wound therapy on open fractures of the lower limb. Singapore Med J 2013;54(11):620-623

12 Stannard JP, Volgas DA, Stewart R, McGwin G Jr, Alonso JE. Negative pressure wound therapy after severe open fractures: a prospective randomized study. J Orthop Trauma 2009;23(8):552-557

13 Blum ML, Esser M, Richardson M, Paul E, Rosenfeldt FL. Negative pressure wound therapy reduces deep infection rate in open tibial fractures. J Orthop Trauma 2012;26(9):499-505

14 DeFranzo AJ, Argenta LC, Marks MW, et al. The use of vacuum-assisted closure therapy for the treatment of lowerextremity wounds with exposed bone. Plast Reconstr Surg 2001;108(5):1184-1191

15 Herscovici D Jr, Sanders RW, Scaduto JM, Infante A, DiPasquale T. Vacuum-assisted wound closure (VAC therapy) for the management of patients with high-energy soft tissue injuries. J Orthop Trauma 2003;17(10):683-688

16 Lalezari S, Lee CJ, Borovikova AA, et al. Deconstructing negative pressure wound therapy. Int Wound J 2017;14(4):649-657

17 Orgill DP, Manders EK, Sumpio BE, et al. The mechanisms of action of vacuum assisted closure: more to learn. Surgery 2009; 146(1):40-51

18 Peinemann F, Sauerland S. Negative-pressure wound therapy: systematic review of randomized controlled trials. Dtsch Arztebl Int 2011;108(22):381-389

19 Kairinos N, Solomons M, Hudson DA. Negative-pressure wound therapy I: the paradox of negative-pressure wound therapy. Plast Reconstr Surg 2009;123(2):589-598, discussion 599-600

20 Anesäter E, Borgquist O, Hedström E, Waga J, Ingemansson $\mathrm{R}$, Malmsjö M. The influence of different sizes and types of wound fillers on wound contraction and tissue pressure during negative pressure wound therapy. Int Wound J 2011;8(4):336-342

21 Lancerotto L, Bayer LR, Orgill DP. Mechanisms of action of microdeformational wound therapy. Semin Cell Dev Biol 2012;23(9):987-992

22 Erba P, Ogawa R, Ackermann M, et al. Angiogenesis in wounds treated by microdeformational wound therapy. Ann Surg 2011;253(2):402-409

23 Saxena V, Hwang CW, Huang S, Eichbaum Q, Ingber D, Orgill DP. Vacuum-assisted closure: microdeformations of wounds and cell proliferation. Plast Reconstr Surg 2004;114(5):10861096, discussion 1097-1098

24 Yang SL, Han R, Liu Y, Hu LY, Li XL, Zhu LY. Negative pressure wound therapy is associated with up-regulation of bFGF and ERK1/2 in human diabetic foot wounds. Wound Repair Regen 2014;22(4):548-554 
25 Wiegand C, White R. Microdeformation in wound healing. Wound Repair Regen 2013;21(6):793-799

26 Lu F, Ogawa R, Nguyen DT, et al. Microdeformation of threedimensional cultured fibroblasts induces gene expression and morphological changes. Ann Plast Surg 2011;66(3):296-300

27 Johnson KE, Wilgus TA. Vascular endothelial growth factor and angiogenesis in the regulation of cutaneous wound repair. Adv Wound Care (New Rochelle) 2014;3(10):647-661

28 Wang W, Pan Z, Hu X, Li Z, Zhao Y, Yu AX. Vacuum-assisted closure increases ICAM-1, MIF, VEGF and collagen I expression in wound therapy. Exp Ther Med 2014;7(5):1221-1226

29 Kim BS, Pallua N, Bernhagen J, Bucala R. The macrophage migration inhibitory factor protein superfamily in obesity and wound repair. Exp Mol Med 2015;47:e161

30 Yukitake H, Takizawa M, Kimura H. Macrophage migration inhibitory factor as an emerging drug target to regulate antioxidant response element system. Oxid Med Cell Longev 2017;2017:8584930

31 Grimm A, Dimmler A, Stange S, et al. Expression of HIF-1 alpha in irradiated tissue is altered by topical negative-pressure therapy. Strahlenther Onkol 2007;183(3):144-149
32 Ma Z, Shou K, Li Z, Jian C, Qi B, Yu A. Negative pressure wound therapy promotes vessel destabilization and maturation at various stages of wound healing and thus influences wound prognosis. Exp Ther Med 2016;11(4):1307-1317

33 Xia CY, Yu AX, Qi B, Zhou M, Li ZH, Wang WY. Analysis of blood flow and local expression of angiogenesis-associated growth factors in infected wounds treated with negative pressure wound therapy. Mol Med Rep 2014;9(5):1749-1754

34 Britland S, Ross-Smith O, Jamil H, Smith AG, Vowden K, Vowden P. The lactate conundrum in wound healing: clinical and experimental findings indicate the requirement for a rapid point-of-care diagnostic. Biotechnol Prog 2012;28(4):917-924

35 Hunt TK, Aslam RS, Beckert S, et al. Aerobically derived lactate stimulates revascularization and tissue repair via redox mechanisms. Antioxid Redox Signal 2007;9(8):1115-1124

36 Zabel DD, Feng JJ, Scheuenstuhl H, Hunt TK, Hussain MZ. Lactate stimulation of macrophage-derived angiogenic activity is associated with inhibition of Poly(ADP-ribose) synthesis. Lab Invest 1996;74(3):644-649

37 Trabold $\mathrm{O}$, Wagner S, Wicke $\mathrm{C}$, et al. Lactate and oxygen constitute a fundamental regulatory mechanism in wound healing. Wound Repair Regen 2003;11(6):504-509 